\title{
The Research of Innovation Ability on Engineering Students in Second Classroom
}

\author{
Yue TANG, Guang-Yi LIN, Zhi-Hua LI, Zhong-Ke TIAN \\ Shandong Provincial Key Laboratory of Polymer Matirial Advanced Manufacturing Technology, \\ College of Electromechanical Engineering, Qingdao University of Science and Technology \\ Qingdao, 266061, China \\ kedaty@126.com
}

Keywords: Second classroom, Engineering students, linnovation Ability.

\begin{abstract}
Based on the international engineering high education requirement, this paper takes the second class as the main line, from the starting point on the problem of talent cultivation in engineering and mechanical universities. Through reform of teaching mode, explored how to improve students' enthusiasm for learning, through extending first classroom to second classroom, explored ways how to consolidate and strengthen the learning effect of engineering students, through combining the theory with practice, explored how to the study of engineering students combine with the industry in the future. The results showed: a good second classroom design and implementation is good for students' education. It is conducive to the improvement of students' practical ability and innovation ability. It is favor of students' employment and entrepreneurship.
\end{abstract}

\section{Introduction}

Into the 21 st century, the world's industrial transformation, in the field of science and engineering innovation and so on, the competition is becoming increasingly fierce, the quality requirements of talents in engineering colleges and universities are also continuously improved. The key to cultivating excellent talents in engineering is the ability of talent and creativity. Engineering students are the backbone of the national manufacturing reserve. Their knowledge structure and innovation ability play an important role in the country's prosperity. College students receive theoretical knowledge in the first classroom, the second class is an extension of the first class [1].In this paper, for engineering students how to enhance the teaching effect of first class through the second classroom, perfect knowledge structure. To explore how to improve students' learning ability in education in modern engineering, how to improve students' ability to practice and innovate. It is a good foundation for students to study, work or start a business after graduation.

\section{Overview of the Training Mode of Engineering Students in Abroad and China}

\section{Practical Teaching Model of Foreign Engineering Universities}

In the United States, the university education is the liberal education, and the employment of students is wide. There are many mechanical courses, such as energy engineering, space technology, fluid mechanics, solid mechanics and environmental engineering. After studying the basic mechanics course and technical courses, student can choose more specialized courses that are he's more interesting. When students need to master a particular technology he can enter the lab directly or enter a business practice near the university [2].In Germany, engineering universities attach great importance to the practice of professional technology. Undergraduates in applied engineering need to go to the society or enterprises for engineering training in half the time, most of the students' graduation designs come from industry [3].In Japan, engineering education attaches great importance to application technology research how to translate into application technology, how to develop new product [4].In the UK, education of engineering university attaches great importance to practice, and the proportion of total teaching content in practice teaching is larger [5].People in 
the education industry believe that social and economic development requires not only scientists but also engineers with hands-on and creative skills.

In the developed countries, more research is on how to exert the potential of students to adapt to the development of enterprises and social needs.

\section{Problems Existing in Teaching Practice of Engineering Students in China}

In China, engineering colleges have given more students an opportunity to accept education after the elite education has turned to popularizing education. Let more students have the opportunity to accept education, but due to the large number of students, the relative lack of human, financial and material resources, the teaching theoretical knowledge of engineering has a large proportion, and the practice link is weak. In the case of mechanical courses, the practical content of its curriculum setting from the original curriculum experiment, curriculum design, professional knowledge internship, professional production practice and graduation practice, to professional knowledge internship and professional production internship merger, to graduation internship cancelled. This causes students failed to personally experience the several important professional engineering practice process is out of the college. Students to create opportunities for less during the period of college to participate in. So, the graduates cannot find satisfactory work, and the employer is not able to find satisfied graduates [7]. The students' perceptual knowledge of the processing process is lack, and the innovation ability is restricted. China's engineering higher education has yet to be improved in practice.

\section{Exploration for Innovation Mode in Second Class Design and Practice}

After an understanding of the learning situation of college students, it was found that some college students were not fully aware of their major after entering the university, not knowing the purpose of learning, and losing interest in learning. Especially for mechanical students of engineering, the learning process is more theoretical and more formulaic, the learning process is boring, and the internship condition is poor, resulting in the students' lack of interest. In college, practical engineering participation is less, perceptual knowledge is less, professional knowledge is less, the ability to solve the problem is weak. In order to solve the above problems. We the development of the second classroom, solve students' goal is not clear, learning motivation, from rational to perceptual knowledge connection is weak, lead to students' cognitive ability and solving complex problems of the weak, the problem such as innovation ability is not strong. Mechanical and electrical engineering department of Qingdao University of science and technology has been piloted in the teaching mode of "mechanical talents class". The second classroom practice teaching link is added. Design second class teaching content by a professional tutor, exploring how to improve students' learning interest and understanding of engineering through the second classroom, how to improve the engineering student systems learning and innovation in the second class, how to improve students' practical ability and innovation ability in the second class. Through this research, it can promote the combination of extracurricular practice innovation and classroom learning content, integrating engineering students' classroom theory with open practice learning to improve students' learning ability, to improve employment and innovation capacity.

\section{Influences on Professional Practice and Innovative Thinking of Students in the Second Class}

\section{Establish Contact between Second Class and Professional Class}

The traditional first class teaching mode focuses on students' basic theory and knowledge reserve. In class teaching of engineering machinery, spatial thinking is complicated, the monotonous teaching mode makes learning content boring and knowledge difficult to master. The following exploratory work was carried out in the second class :(1) Major advance introduction reform. The teaching link will be introduced into the professional courses after the original courses. Instead, it will be introduced in a brief introduction to mechanical and professional courses. The special course tutor makes a second class special introduction, which establishes the contact between the student 
and the special topic tutor, and builds the second classroom platform. (2) Introduction of the reform of the industry problems. After the students and professional tutors are connected, the professional questions are presented to the students by the tutor. For example, environmental problems in production, energy consumption, energy saving and so on. These make students have a preliminary understanding of mechanical and polymer processing machinery (specific professional direction), and think positively.(3) relevance reform of basic courses and specialized courses. The tutor changed the teaching mode of single subject teaching in the past, and guided the students to devote their leisure time to the study of basic knowledge and important courses. For example: mechanical drawing, mechanical parts, mechanical principles, Pro/E, AuotCAD system basic courses and technical basic courses in series .Mentor by setting subject also guide them to focus on understanding dynamic mechanism and related industries, gradually make students' thinking into the industry and professional, in the second classroom topic for discussion so that the students into the positive learning environment.

\section{To Build the Second Classroom Practice Base in the Enterprise}

In order to enable students to have an intuitive sense of the field of the professional, the professional tutors to establish an internship base with enterprises. After completing basic courses in the second grade, students can enter into professional production enterprises under the guidance of their tutors, and can conduct short-term internships in professional companies. When students enter the enterprise, they directly watch and understand the whole process of producing a product. For example, a rubber product - a tire, from the initial mixing of the final tire out of the place requires a series of processes. This gives them a clearer understanding of what they have learned and the problems they have in their production and production. In order to be able to participate in the problem of production as soon as possible, carry out the solution demonstration, the students realized that they should have a solid theoretical knowledge and basic background of technical basic courses, so that they began to have a strong interest in the basic courses of learning technology and the motivation for graduate college.

\section{The Combination of Classroom Teaching and Training Objectives}

The traditional first class teaching mode focuses on students' basic theory and knowledge reserve. In class teaching of engineering machinery, spatial thinking is complicated, the monotonous teaching mode makes learning content boring and knowledge difficult to master.

According to the new development goals for mechanical engineering students:(1) students should be able to use mathematics, natural science and engineering basic theories to understand and solve complex engineering problems in the field of mechanical engineering in the context of society;(2) possess engineering practice and innovation ability, and use modern tools for research and development, design and manufacturing, operation and management of mechanical and polymer materials processing machinery;(3) having good humanistic and scientific literacy, teamwork ability and certain international vision, able to actively adapt to social development and environmental changes, and have continuous learning ability. In the training target, strengthen the combination of in-class and after-class teaching and research, the combination of students' scientific research training, cultivating students' ability of autonomous learning and innovation research learning, to adapt to the internationalization of unit of choose and employ persons and broader the employer's requirements. The following works are done:(1) in the second classroom, the teacher let the students directly involved in the scientific research project, communication with students regularly. In the professional knowledge study period, the students have a certain knowledge of profession, in normal times would begin to pay close attention to industry information.(2) in the second classroom, the tutor guides the students to conduct autonomous learning and daily report learning effect. Students also learn about the social problems they need to solve and get into exploratory learning.(3) in the second classroom, combining with the teacher's project, the students in the research work with the tutor, combined with their own knowledge and practice, will carry out discussion studies.(4) In the second classroom, students are carry out research projects and participating in various 
practical mechanical innovation competitions. The students formed research group, independently conducted research, program demonstration, theoretical application and computer simulation, and carried out prototype making (innovation practice objectification). By revising and summarizing, they have repeated multiple times, carried out practice and summary study, and strengthened the learning effect and yielded fruitful research results.

\section{The Second Class Combines with Professional Research Projects}

The students actively participate in the second classroom teaching practice, focus on the industry(the project participated in the semester of junior year), for example, students participated in the practice of recycling waste rubber installations, participated in the national 3D design competition and so on. The students apply the design software has been designed with the prototype model. The installation interferometric analysis of the prototype, the analysis of the motion analysis of the finite element device, the analysis of the stress state of the key parts and the operation analysis of the prototype, etc. Students participate in a series of professional research projects and practice innovation competitions. They took full advantage of their spare time. The recognition of the major has also risen to a new level. Not only have they applied what they have learned, the ability to operate improved, and the ability to operate software improved, but also apply their knowledge innovation to new technology design, new software design. The students innovative thinking ability improved, the teaching effect improved

\section{Innovation Results in the Second Class}

Over the past four years, the teacher has been following the student's study and the learning of them in the second classroom. From the beginning of students' admission to the university, organize the students to connect with the enterprise tutors in the second class, to participate in the enterprise training and participate in the teacher project. The students not only interest in learning but also improved learning effect. They have achieved a number of innovations. They got 2 national innovation training programs during their university period, provincial innovation project 1 , university-level innovation project 1, declaration and approval of 2 patents, obtaining software copyright 4 items. These are the licenses of the undergraduate students to get approval patents and software. They also won the second prize in the national 3D design competition, Shandong province special prize 1 . The achievement of these achievements has played an important role in promoting students' entrepreneurship and employment, which has comprehensively improved students' professional knowledge and innovation ability.

In "Elite class", there are 24 students. All students participated in the second class innovation project. By the end of the first semester of the fourth year, there were 13 students enrolled in 211 universities and 4 postgraduate students, 3 overseas graduate students (including 1 at Boston University, 1 in Germany, 1 in Japan), 2 students were accepted by the best companies in the local industry. On the eve of graduation, students said that "the second class has no substitute for the first class". The above data shows that, through the addition of a second classroom of professional teaching, students continue to study at home and abroad, and the employment rate reaches $96 \%$. The second class has gained a good teaching effect.

Therefore, the implementation and design of the second class are conducive to the improvement of students' learning ability, to the improvement of students' ability of practice, innovation ability and employment. The implementation and design of the second class is conducive to the cultivation of innovative talents.

\section{References}

[1] Mei-chen AN, Wei-guo ZHANG. Analysis on university second class education [J], Education Exploration. (2016) (5):91-93.

[2] Kun LI,Dahu CAO. Analysis of China's normal university engineering professional education 
from the American higher education popular $[\mathrm{J}]$, Science and Technology Innovation Herald. (2008)(16):204-205.

[3] Jingzhi DING. To analyze the education behavior of people in engineering fields in German universities [J], Higher Education Research. (2009) (1):17-19.

[4] Han-bing KONG, Bi-jin ZOU, Pei-min WANG. The Academic Structure and Innovation of Science and Technology in Tokyo University [J], Joumal of Xi'an Jiaotong University (Social Sciences). 22(2002) (1):93-96.

[5] Zhong-ning GUO. Approaching British's Universities - An Investigation Report on the education of Science and Engineering in Britain[J], Joumal of Guangdong University of Technology (Social Sciences Edition)(2005)5(2):1-5.

[6] Yu-fei FANG. The Problems Existing in the College Students' Career Education [J], Modern University Education (2013) (4):104-110.

[7] Xin-tao LAI. Innovative Design for Second Class Activities at Local Undergrad College [J], Journal of Sanming University.33 (2016) (6):7-11. 